Research article

\title{
High incidence of Epstein-Barr virus, cytomegalovirus and human herpesvirus 6 infections in children with cancer Jaroslav Michálek ${ }^{* 1}$ and Radek Horvath ${ }^{2}$
}

Address: ${ }^{1}$ Department of Pediatrics, Division of Hematology/Oncology, Masaryk University, Brno, Czech Republic and ${ }^{2}$ Laboratory of Genetics and Molecular Biology, Center for Cardiovascular and Transplant Surgery, Brno, Czech Republic

E-mail: Jaroslav Michálek* - jaroslav.michalek@utsouthwestern.edu; Radek Horvath - horvathr@seznam.cz

${ }^{*}$ Corresponding author

Published: 10 January 2002

BMC Pediatrics 2002, 2:1
Received: 4 August 200I

Accepted: 10 January 2002

This article is available from: http://www.biomedcentral.com//47I-243I/2/I

(c) 2002 Michálek and Horvath; licensee BioMed Central Ltd. Verbatim copying and redistribution of this article are permitted in any medium for any non-commercial purpose, provided this notice is preserved along with the article's original URL. For commercial use, contact info@biomedcentral.com

\begin{abstract}
Background: A prospective single-center study was performed to study infection with lymphotropic herpesviruses (LH) Epstein-Barr virus (EBV), cytomegalovirus (CMV) and human herpesvirus 6 (HHV-6) in children with cancer.

Methods: The group of 186 children was examined for the presence of $\mathrm{LH}$ before, during and 2 months after the end of anticancer treatment. Serology of EBV and CMV was monitored in all children, serology of HHV-6 and DNA analysis of all three LH was monitored in 70 children.

Results: At the time of cancer diagnosis (pre-treatment), there was no difference between cancer patients and age-matched healthy controls in overall lgG seropositivity for EBV (68.8\% vs. $72.0 \%$; $p$ $=0.47)$ and CMV (37.6\% vs. $41.7 \%$; $=0.36)$. During anticancer therapy, primary or reactivated EBV and CMV infection was present in 65 (34.9\%) and 66 (35.4\%) of 186 patients, respectively, leading to increased overall post-treatment $\lg \mathrm{g}$ seropositivity that was significantly different from controls for EBV (86.6\% vs. $72.0 \%$; $=0.0004)$ and $\mathrm{CMV}(67.7 \%$ vs. $41.7 \%$; $p<0.0001)$. Overall pre-treatment $\lg$ seropositivity for HHV-6 was significantly lower in patients than in controls $(80.6 \%$ vs. $91.3 \% ; p=0.0231)$ which may be in agreement with Greaves hypothesis of protective effect of common infections in infancy to cancer development. Primary or reactivated HHV-6 infection was present in 23 (32.9\%) of 70 patients during anticancer therapy leading to posttreatment $\lg G$ seropositivity that was not significantly different from controls ( $94.3 \%$ vs. $91.3 \%$; $\mathrm{p}$ $=0.58$ ). The $\mathrm{LH}$ infection occurred independently from leukodepleted blood transfusions given. Combination of serology and DNA analysis in detection of symptomatic EBV or CMV infection was superior to serology alone.
\end{abstract}

Conclusion: EBV, CMV and HHV-6 infections are frequently present during therapy of pediatric malignancy.

\section{Background}

Extensive bone marrow infiltration with cancer cells and anticancer therapy lead to immune incompetence in children with cancer $[1,2]$. Since the prognosis and overall survival of children with cancer have dramatically improved during past 30 years [3], problems remain related to infections, mainly during leukopenic periods [3-5]. Causal pathogens of febrile neutropenia (FN), most fre- 
quently bacterial or fungal, are identified and confirmed by culture in $25-35 \%$ of the cases [3,6]. In other $15-25 \%$ of patients with FN, bacterial or fungal pathogens are suspected clinically. The remaining $50 \%$ of cases are classified as a fever of unknown origin (FUO) and may be caused by other pathogens, namely viruses, that are more difficult to detect by conventional diagnostic methods [79].

Lymphotropic herpesviruses (LH) Epstein-Barr virus (EBV), cytomegalovirus (CMV) and human herpesvirus-6 (HHV-6) establish a lifelong persistent infection in a great majority of humans. They usually produce inaparent infection or transient immune compromise in otherwise healthy hosts but are able to cause life-threatening primary or reactivated infections in individuals with congenital or acquired T-cell immunodeficiencies [7-15]. The spectrum of diseases caused by lymphotropic herpesviruses is well documented in patients undergoing bone marrow transplantation (BMT) [8-11] or organ transplantation $[12,13]$ and in individuals infected with human immunodeficiency virus (HIV) $[14,15]$. In patients undergoing conventional anticancer therapy without BMT, the data focusing on EBV, CMV or HHV-6 infection are scarcely documented and mostly reported as individual cases [16$19]$. With combined diagnostic approach of serology and viral DNA detection we performed a prospective study of children undergoing non-BMT therapy for cancer to demostrate the incidence of LH infections.

\section{Methods}

\section{Patients and controls}

Two hundred and nine Caucasian children and adolescents 4 months to 17 years old at the time of cancer diagnosis were eligible for this prospective Institutional Review Board approved single-center study performed at the Department of Pediatrics, Masaryk University in Brno, Czech Republic. Inclusion criteria for patients included: presence of cancer, serology of EBV and CMV at least at the time of cancer diagnosis (pre-treatment sample) and 2 months after the end of anticancer therapy (post-treatment sample). Children with cancer undergoing BMT, human immunodeficiency virus positive children, and children who died while on anticancer therapy were excluded from the study. All children were treated according to approved current protocols for therapy of pediatric malignancies (Berlin-Frankfurt-Münster protocols for therapy of leukemia and non-Hodgkin's lymphoma; Histiocyte Society protocols for therapy of histiocytoses; International Pediatric Oncology Society protocols for treatment of Hodgkin's disease and solid tumors except for neuroblastoma which has been treated according to Pediatric Oncology Group protocols). As a supportive care, leukodepleted (containing $<10^{5}$ leukocytes per one transfusion unit) irradiated (50Gy) blood products (packed red blood cells; platelets obtained by apheresis from one donor) were given only. Finally, 186 children and adolescents, 101 males and 85 females, met the inclusion criteria; remaining 23 children did not meet that criteria since they move or their initial or follow-up samples were missing.

One hundred and sixteen consecutive patients were studied from 1993 through 1996. In addition, in consecutive 70 patients studied from 1997 through 1999, serology of HHV- 6 at the same time-points as for EBV and CMV, and monitoring of EBV, CMV and HHV-6 DNA was also performed. If a sample was positive for LH DNA, repeated samples every 5-7 days were performed until negative. During anticancer therapy, samples of peripheral blood for serology and LH DNA study were taken as clinically indicated in the following situations: (1) FN (defined as a single episode of oral temperature $\geq 38.5^{\circ} \mathrm{C}$ or at least two episodes of oral temperature $\geq 38^{\circ} \mathrm{C}$ appearing at least 12 hours apart in a patient with absolute neutrophil count $\leq$ $500 / \mathrm{ml}$ ); (2) fever of unknown origin (FUO) (defined as oral temperature $\geq 37^{\circ} \mathrm{C}$ lasting for at least 7 days and no infectious or non-infectious cause of the fever has been identified); (3) lymphadenopathy, hepatomegaly or splenomegaly not associated directly with the diagnosis or relapse of the cancer; (4) liver enzymes (aspartataminotransferase or alaninaminotransferase) elevation above 2 standard deviations of normal values; (5) protracted ( $\geq$ 14 days) bone marrow aplasia (defined as presence of at least two of the following: leukocytes $\leq 1,000 / \mathrm{ml}$, thrombocytes $\leq 30,000 / \mathrm{ml}$, hemoglobin $\leq 80 \mathrm{~g} / \mathrm{l}$ in peripheral blood) without the evidence of chemotherapy- or radiotherapy-induced aplasia; (6) gastroenteritis; (7) atypical pneumonia; (8) exanthema; and (9) encephalopathy. Infection associated with at least one of the symptoms mentioned above and confirmed by serology or in combination with viral DNA detection was designated as "symptomatic infection".

The population was studied according to cancer diagnosis (leukemia, lymphoma and solid tumor) and according to the age at the time of a particular sample has been taken. Based on age at the time when a pre-treatment sample was taken, four age groups has been made: $0-1$ year old (consisting of 25 children); $2-5$ years old ( 49 children); 6-11 years old (52 children); and 12-17 years old (60 children). A total of 218 children 4 months to 17 years old $(31,54,62,71$ children in age group $0-1,2-5,6-11,12-$ 17 years, respectively) and 165 adults $19-78$ years old without infectious or febrile illness who underwent minor surgery procedure and provided a blood sample for that purpose, served as a healthy controls for serology testing. 64 children from that group provided samples of peripheral blood for LH DNA analysis too. Informed consent has 
been taken from all adults and parents/legal guardians of all the children.

\section{Serology of $\mathbf{L H}$}

All samples were tested by commercially available sets. ELISA testing kit (DIESSE ${ }^{\circledast}$, Germany) was used to test the EBV VCA IgM, EBV VCA IgG, EBV EBNA IgG antibodies [20] and ELISA testing kit (MEDAC ${ }^{\circledR}$, Czech Republic) was used to test the CMV IgM and CMV IgG antibodies in patient sera [21]. Immunofluorescence assay (IFA) kit (BAG ${ }^{\circledast}$, Germany) was used to test the HHV-6 IgM and HHV-6 IgG antibodies [22]. All tests were performed according to manufacturer's instructions. To avoid misinterpretation of results, all samples from each patient were titrated and tested at the same time. The titer results were expressed semiquantitatively in four grades: negative(-); mildly positive $(+)$; moderately positive $(++)$; strongly positive $(+++)$ for each antibody tested.

The presence of EBV VCA IgM positivity (of any grade) followed by EBV VCA IgG positivity (of any grade) or increasing EBV VCA IgG positivity with negative EBV EBNA IgG 14-21 days after an initial level was measured was considered as a recent primary EBV infection. EBV EBNA IgG positive (of any grade) case with the presence of the same pattern of EBV VCA IgM and/or EBV VCA IgG positivity as in the primary infection was considered as an EBV reactivation. In case of CMV and HHV-6, the presence of IgM class antibody positivity (of any grade) followed by IgG positivity (of any grade), or increasing IgG positivity 14-21 days after an initial level was measured, was considered as a primary CMV or HHV-6 infection. IgM positivity (of any grade) in a patient previously IgG positive was considered as a reactivation of CMV or HHV-6.

\section{DNA analysis of $\mathbf{L H}$}

Whole blood samples were collected in $\mathrm{K}_{3}$ EDTA tubes (Sarstedt). Nucleic acids were isolated using silica-based Nucleic Acids Isolation Kit (Malamite, Czech Republic). For EBV DNA detection two primer pairs EBER 3 (5' gca acg gct gct ctg ttt ga), EBER 5 (5' gtg gtc cgc atg ttt tga tc) and TC60 (5' cca gag gta agt gga ctt), TC61 (5' gac cgg tgc $\mathrm{ctt} \mathrm{ctt}$ agg) were used. The lengths of EBER- and TC6-specific amplification products were $192 \mathrm{bp}$ and $119 \mathrm{bp}$, respectively. The HCMV DNA was detected using HCMV1 (5' cct agt gtg gat gac cta cgg gcc a) and HCMV2 (5' cag aca cag tgt cct ccc get cct c) primers producing 249 bp long amplicon and the DNA of HHV6 was amplified with specific primer pair HPO (5' ccg caa tcg aat cca cct agc gg) and HP4 ( 5 ' gtg aga acg gat tcg aac agt gct g) yielding 440 bp product $[23,24]$. All amplifications were carried out with 20 pmol of each primer in $2 \mathrm{mM}$ solution of $\mathrm{MgCl}_{2}, 2 \mathrm{U}$ of Tag Special DNA polymerase (Biovendor, Czech Republic), $0.3 \mathrm{mM}$ of each dNTPs, $10 \times$ reaction buffer and $1 \mu \mathrm{g}$ of isolated DNA according to the following conditions: $96^{\circ} \mathrm{C}$ for $4 \mathrm{~min},\left(94^{\circ} \mathrm{C}\right.$ for $10 \mathrm{sec}, 58^{\circ} \mathrm{C}$ for $10 \mathrm{sec}, 72^{\circ} \mathrm{C}$ for $20 \mathrm{sec}) 36$ times, and final extension at $72^{\circ} \mathrm{C}$ for $2 \mathrm{~min}$. The reactions were done in the thermocycler PTC 200 (M) Research). The products amplified were run on 3\% agarose gel (Lachema, Brno, Czech Republic) and detected by UV illuminator at $312 \mathrm{~nm}$ after staining with ethidium bromide $(5 \mu \mathrm{g} / \mathrm{ml})$. Electrophoretograms were scanned by CCD camera (UltraLum) and the relative quantities were estimated (expressed as follow: $(+)=$ under 100, $(++)$ from 100 to $10,000,(+++)=$ more than 10,000 viruses per $10^{5}$ peripheral leukocytes processed) according the densities of pathogen-specific bands measured by Scionlmage ${ }^{\circledast}$ software, using the standard curves of positive controls, which were derived from 10-fold dilution scales. The set of "negative control" ( $1 \mu \mathrm{l}$ of water instead of isolated DNA), "negative isolation control" (virus-free blood sample) and "inhibition controls" ( $1 \mu \mathrm{l}$ of each isolate added in the reaction with $1 \mu \mathrm{l}$ of positive control DNA) as well as the "positive control" (only with $1 \mu$ l of positive control DNA = recombinatnt plasmids with inserted amplicons) was additionaly amplified to reduce the risk of false positive and/or false negative results. Any positivity detected by PCR followed by serology results demonstrating recent LH infection 1 to 5 weeks later was considered as an active infection.

\section{Statistical analysis}

Unconditional logistic regression analysis was performed with pre-treatment (presence or absence of virus) as the dichotomous outcome measure. For this analysis group (patients or controls), age (as a continuous variable), and the interaction of age and group were the independent measures. This analysis was repeated for each viral serology. To control for age, logistic regressions were performed within each age group $(0-1 ; 2-5 ; 6-11$; and $12-17)$ for each viral serology with group as the only independent variable. These analyses provide estimates and confidence intervals of the odds ratios of seroprevalence for pre-treatment cases versus controls adjusting for age. The same set of analyses was performed with post-transplant cases versus controls.

To study pre-treatment versus post-treatment patient samples, a McNemar test was performed for each viral serology. McNemar's test determines the degree of agreement between two paired variables. This test was performed both overall, ignoring age, and then repeated within each age group. For the comparison of transfused and nontransfused patients, chi-square test was used [25].

\section{Results}

186 children aged 4 months to 17 years met the inclusion criteria and were evaluated for the presence of LH infection during treatment of their cancer. There were 101 boys and 85 girls 4 months to 17 years old with a mean age 
Table I: Patient and control characteristics.

\begin{tabular}{|c|c|c|c|}
\hline Cancer diagnosis & Number of patients & Mean age and range* & Treatment duration - mean and range ${ }^{* *}$ \\
\hline Leukemia group - total & 77 & $6.44(0.5-16.0)$ & $1.54(0.7-2.2)$ \\
\hline - Acute lymphoblastic leukemia & 62 & & \\
\hline - Acute myeloid leukemia & 14 & & \\
\hline - Myelodysplastic syndrome & 1 & & \\
\hline Lymphoma group - total & 42 & | $2.07(2.0-17.8)$ & $0.81(0.6-1.0)$ \\
\hline - Hodgkin's disease & 27 & & \\
\hline - Non-Hodgkin's lymphoma & 15 & & \\
\hline Histiocytosis group - total & 9 & $3.34(0.3-12.7)$ & $0.72(0.5-1.0)$ \\
\hline - Class I. & 7 & & \\
\hline - Class II. & 2 & & \\
\hline Solid tumor group - total & 58 & $7.4 I(0.7-17.5)$ & $0.96(0.5-2.0)$ \\
\hline - Brain tumors & 21 & & \\
\hline - Neuroblastoma and PPNET'*** & 10 & & \\
\hline - Wilms tumor & 7 & & \\
\hline - Soft tissue sarcoma & 7 & & \\
\hline - Retinoblastoma & 5 & & \\
\hline - Osteosarcoma & 5 & & \\
\hline - Ewing sarcoma & 3 & & \\
\hline Total & 186 & 7.86(0.3-17.5) & I.I $5(0.5-2.2)$ \\
\hline Controls - pediatric & 218 & $8.21(0.3-17.3)$ & - \\
\hline - adult & 165 & $47.53(19-78)$ & - \\
\hline
\end{tabular}

* Mean age in years at the time of cancer diagnosis; (range). ${ }^{* *}$ Mean interval in years between sample taken at the time of cancer diagnosis and the time 2 months after the completion of anti-cancer treatment; (range). ${ }^{* * *} 8$ patients with neuroblastoma ( 2 patients with stage II., 2 patients with stage III. and 4 patients with stage IV.) and 2 patients with PPNET = peripheral primitive neuroectodermal tumor.

Table 2: Unconditional logistic regression analysis for age groups.

\begin{tabular}{|c|c|c|c|c|c|c|c|}
\hline \multirow[t]{2}{*}{ Virus } & \multirow[t]{2}{*}{ Age group } & \multicolumn{3}{|c|}{ Pre-treatment } & \multicolumn{3}{|c|}{ Post-treatment } \\
\hline & & $\mathrm{P}$-value & OR & odds $\mathrm{Cl}$ & $\mathrm{P}$-value & OR & $\mathrm{Cl}$ \\
\hline \multirow[t]{4}{*}{ EBV } & $0-1$ & 0.89 & 1.09 & $0.27-4.39$ & 0.0008 & 0.1 & $0.03-0.39$ \\
\hline & $2-5$ & 0.73 & 1.15 & $0.52-2.54$ & 0.0118 & 0.29 & $0.11-0.76$ \\
\hline & $6-11$ & 0.64 & 1.23 & $0.5 \mathrm{I}-2.98$ & 0.29 & 0.58 & $0.21-1.60$ \\
\hline & $12-17$ & 0.36 & 1.57 & $0.60-4.17$ & 0.81 & 0.87 & $0.29-2.60$ \\
\hline \multirow[t]{4}{*}{ CMV } & $0-1$ & 0.4 & 1.78 & $0.47-6.79$ & 0.0413 & 0.36 & $0.11-0.96$ \\
\hline & $2-5$ & 0.65 & 1.19 & $0.55-2.61$ & 0.0020 & 0.28 & $0.12-0.63$ \\
\hline & $6-11$ & 0.57 & 1.24 & $0.59-2.59$ & 0.0042 & 0.33 & $0.16-0.7 \mid$ \\
\hline & $12-17$ & 0.71 & 1.14 & $0.57-2.26$ & 0.0272 & 0.45 & $0.22-0.91$ \\
\hline \multirow{4}{*}{$\begin{array}{l}\text { HHV- } \\
6\end{array}$} & $0-1$ & 0.047 I & 3.36 & $1.02-11.1$ & 0.53 & 0.65 & $0 .|7-2.5|$ \\
\hline & $2-5$ & 0.007 I & 5.07 & $1.55-16.5$ & 0.68 & 1.33 & $0.34-5.25$ \\
\hline & $6-11$ & 0.64 & 1.34 & $0.39-4.67$ & 0.54 & 0.63 & $0.14-2.78$ \\
\hline & $12-17$ & 0.92 & 1.07 & $0.27-4.16$ & 0.43 & 0.51 & $0.10-2.75$ \\
\hline
\end{tabular}

7.86 years. Post-treatment samples were taken 0.5 to 2.2 years (mean 1.15 years) after pre-treatment ones. Patient and control characteristics are shown in Table 1.

\section{Serology of $\mathbf{L H}$}

Before grouping the ages, a logistic regression analysis was performed with each viral pre-treatment sample as the dichotomous outcome measure and group (patients or controls) as the independent measure with age as a covariate 
and including the age by group interaction term. There was no statistically significant difference in overall seropositivity between patients and controls for EBV VCA IgG (68.8\% vs. $72.0 \% ; \mathrm{p}=0.47)$ and CMV IgG (37.6\% vs. $41.7 \%$; $\mathrm{p}=0.36$ ) pre-transplant samples. There was a statistically significant difference in the age measure showing that the number of EBV and CMV IgG seropositive cases in pre-treatment samples increases with age $(\mathrm{p}<0.0001$; resp. $\mathrm{p}=0.0131)$. The interaction of age and group measure was not significant ( $\mathrm{p}=0.23$ for EBV and $\mathrm{p}=0.60$ for $\mathrm{CMV}$ ). Overall pre-treatment IgG seropositivity for HHV6 was significantly lower in patients than in controls ( $80.6 \%$ vs. $91.3 \%$; $\mathrm{p}=0.0231)$. The age measure was also significantly different $(\mathrm{p}<0.0001)$ demonstrating increasing HHV-6 IgG positivity with age. The interaction of age and group measure for HHV-6 was not significant $(\mathrm{p}=$ 0.07).

For each age group and each virus, a logistic regression analysis was performed with pre-treatment sample as the dichotomous outcome measure and group (patients or controls) as the independent outcome measure. There were no statistically significant differences between pretreatment patient samples and controls in all age groups for EBV VCA IgG, CMV IgG and in the 6-11 and 12-17 age groups for HHV-6 IgG. The only differences were noticed for HHV-6 in the $0-1$ and 2-5 age groups where patients had lower IgG seropositivity then the controls. Statistical data including p-values, odds ratios and odds confidence intervals are summarized in Table 2.

The same analyses were performed with post-treatment patient samples and controls. There was increased overall post-treatment seropositivity that was significantly different from controls for EBV VCA IgG (86.6\% vs. $72.0 \%$; $\mathrm{p}=$ $0.0004)$ and CMV IgG (67.7\% vs. $41.7 \%$; $<<0.0001)$. No difference in the age measure was found demonstrating that the number of EBV and CMV seropositive cases in post-treatment samples does not increase with age $(\mathrm{p}=$ 0.87 ; resp. $\mathrm{p}=0.62$ ). In case of HHV-6 IgG, no difference was found between post-treatment samples and controls (94.3\% vs. $91.3 \%$; $\mathrm{p}=0.58)$. The age measure was significantly different $(\mathrm{p}=0.0355)$ demostrating increasing HHV-6 IgG seropositivity with age. There was no significant difference in the interaction of age and group measure for EBV, CMV and HHV-6, respectively ( $\mathrm{p}=0.73 ; \mathrm{p}=$ 0.57 ; resp. $\mathrm{p}=0.07$ ).

For each age group and each virus, a logistic regression analysis was performed with post-treatment sample as the dichotomous variable and group (patients or controls) as the independent variable. There were statistically significant differences between post-treatment patient samples and controls in the $0-1$ and 2-5 age groups for EBV VCA IgG and in all age groups for CMV IgG demonstrating higher seropositivity in patients than in controls. No differences were noticed in the 6-11 and 12-17 age groups for EBV VCA IgG and in all age groups for HHV-6 IgG. Statistical data including p-values, odds ratios and odds confidence intervals are summarized in Table 2. Figure 1 demonstrates LH IgG seropositivity in patient pre- and post-treatment samples and in controls.

To compare pre-treatment and post-treatment samples, a McNemar test was performed for each viral serology. This test was performed both overall, ignoring age, and then repeated within each age group. Overall McNemar test demonstrated statistically significant difference between preand post-treatment patient samples for all three LH ( $\mathrm{p}<$ $0.0001)$. There were also statistically significant differences in all age groups for EBV (age group 0-1: $\mathrm{p}=0.0016$; age group 2-5: $\mathrm{p}=0.0003$; age group $6-11: \mathrm{p}=0.0143$; and age group 12-17: $\mathrm{p}=0.0455)$, in all age groups for CMV (age group 0-1: 0.0082; age group 2-5: $\mathrm{p}<0.0001$; age group $6-11: \mathrm{p}<0.0001$; and age group $12-17: \mathrm{p}=$ 0.0003 ) and in two age groups for HHV-6 (age group 0$1: \mathrm{p}=0.0082$; age group 2-5: 0.0016). No significant difference was found in the age group $6-11(\mathrm{p}=0.08)$ and $12-17(\mathrm{p}=0.15)$ for HHV-6. The data are summarized in Figure 1 .

Using the McNemar test, we compared IgG seropositivity between pre-treatment and post-treatment samples according to cancer diagnosis described in Table 1, i.e. leukemias, lymphomas and solid tumors (the group of histiocytosis was not analyzed this way since the number of subjects was too small for statistical analysis). EBV VCA IgG, CMV IgG and HHV-6 IgG seropositivity, respectively, was significantly different in the leukemia group $(\mathrm{p}=$ $0.0004 ; \mathrm{p}<0.0001$; resp. $\mathrm{p}=0.0245)$. There was also a statistically significant difference for CMV IgG in the lymphoma and solid tumor groups $(\mathrm{p}=0.0058$; resp. $\mathrm{p}=$ $0.0008)$. No statistically significant difference was noticed for EBV VCA IgG and HHV-6 IgG in the lymphoma ( $\mathrm{p}=$ 0.36 ; resp. $\mathrm{p}=0.75)$ and solid tumor $(\mathrm{p}=0.25$; resp. $\mathrm{p}=$ 0.12 ) groups. The data are summarized in Figure 2.

Based on serology, we were able to demonstrate the rate of primary infection and reactivation of LH in most of the patients during anticancer treatment. The results are shown in Figure 3. Primary infection with EBV and CMV occurs in almost $50 \%$ of children less than 6 years of age. Primary HHV-6 infection is less frequent. In older children, EBV and HHV-6 reactivation also occurs. We were able to distinguish primary infection from reactivation in all cases of symptomatic EBV infection based on EBNA IgG status. In case of CMV and HHV- 6 there were 4 and 2 cases, respectively, where it was impossible to distinguish that. In addition, two of that cases showed CMV and HHV-6 crossreactivity. 


\section{EBV \\ VCA IgG \\ positive \\ cases}

[\%]
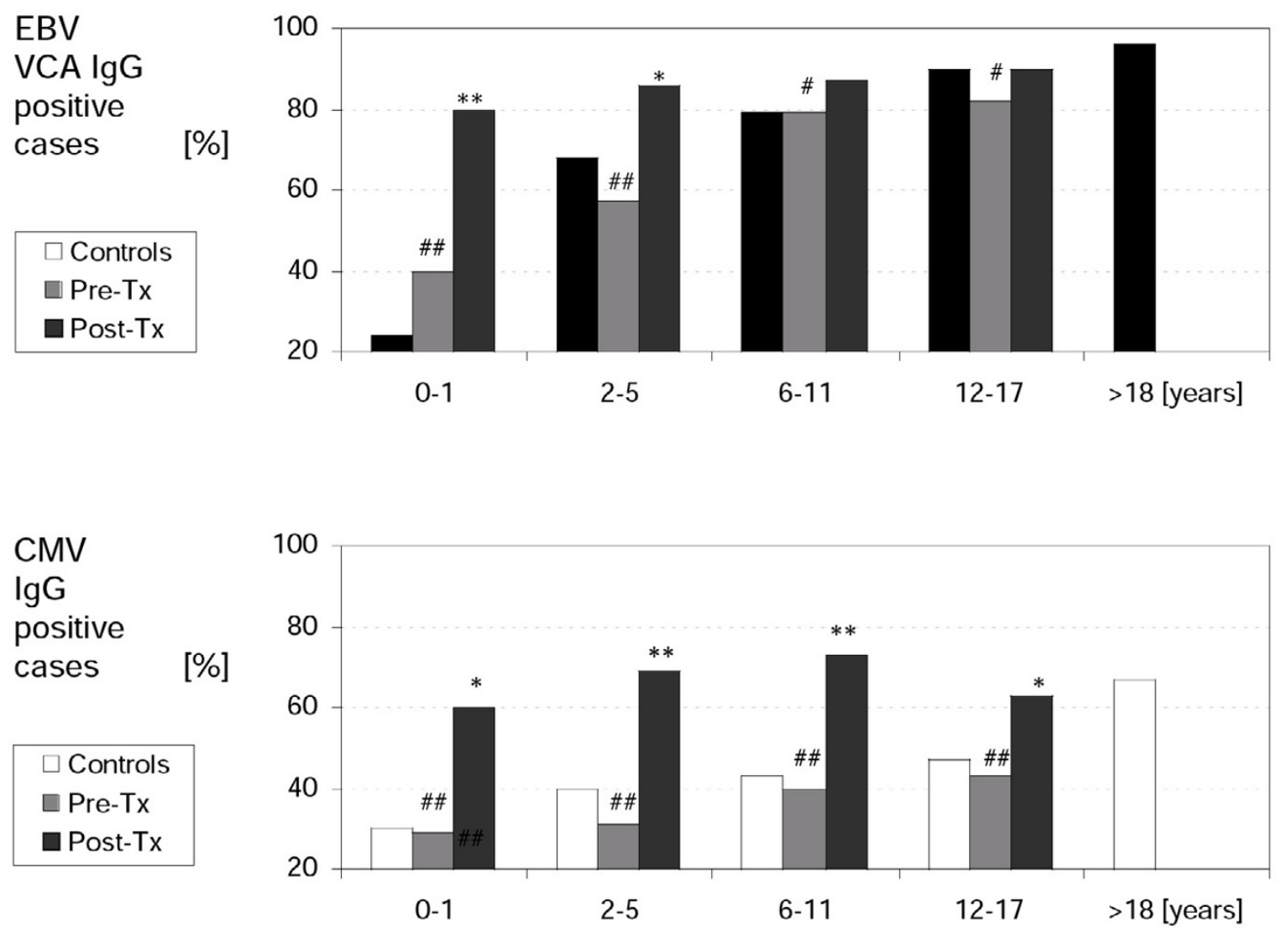

HHV-6
IgG
positive
cases

$\square$ Controls
$\square$ Pre-Tx
$\square$ Post-Tx

[\%]

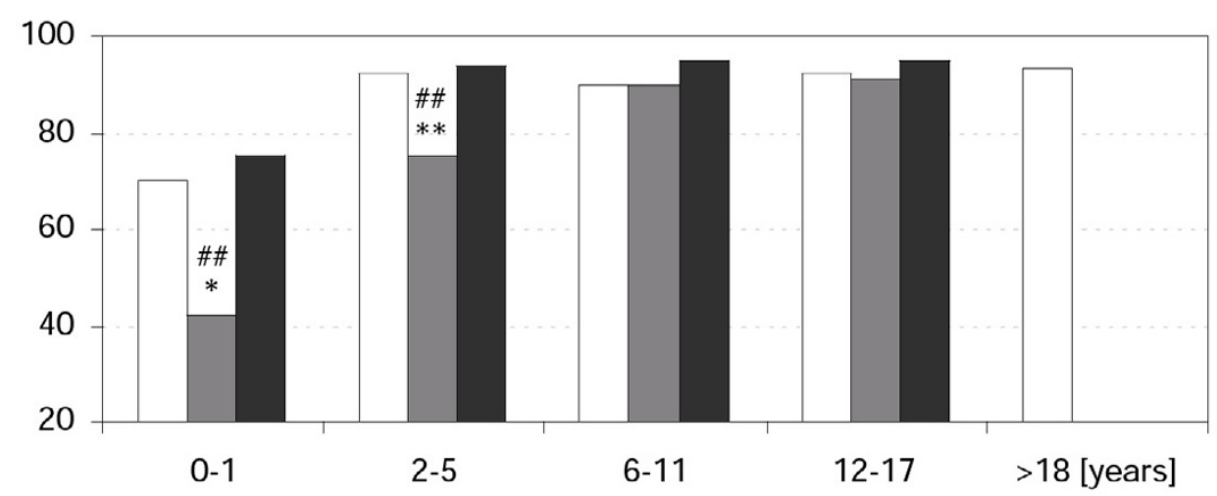

\section{Figure I}

LH serology according to the age. \# $(p<0.05)$, \# $(p<0.0 \mathrm{I})$ statistically significant difference between a group of patients at the time of cancer diagnosis (Pre-Tx) and 2 months after the end of anticancer treatment (Post-Tx). ${ }^{*}(p<0.05)$, ${ }^{* *}(p<0.0 I)$ statistically significant difference between a group of patients and a group of age-matched healthy controls. 

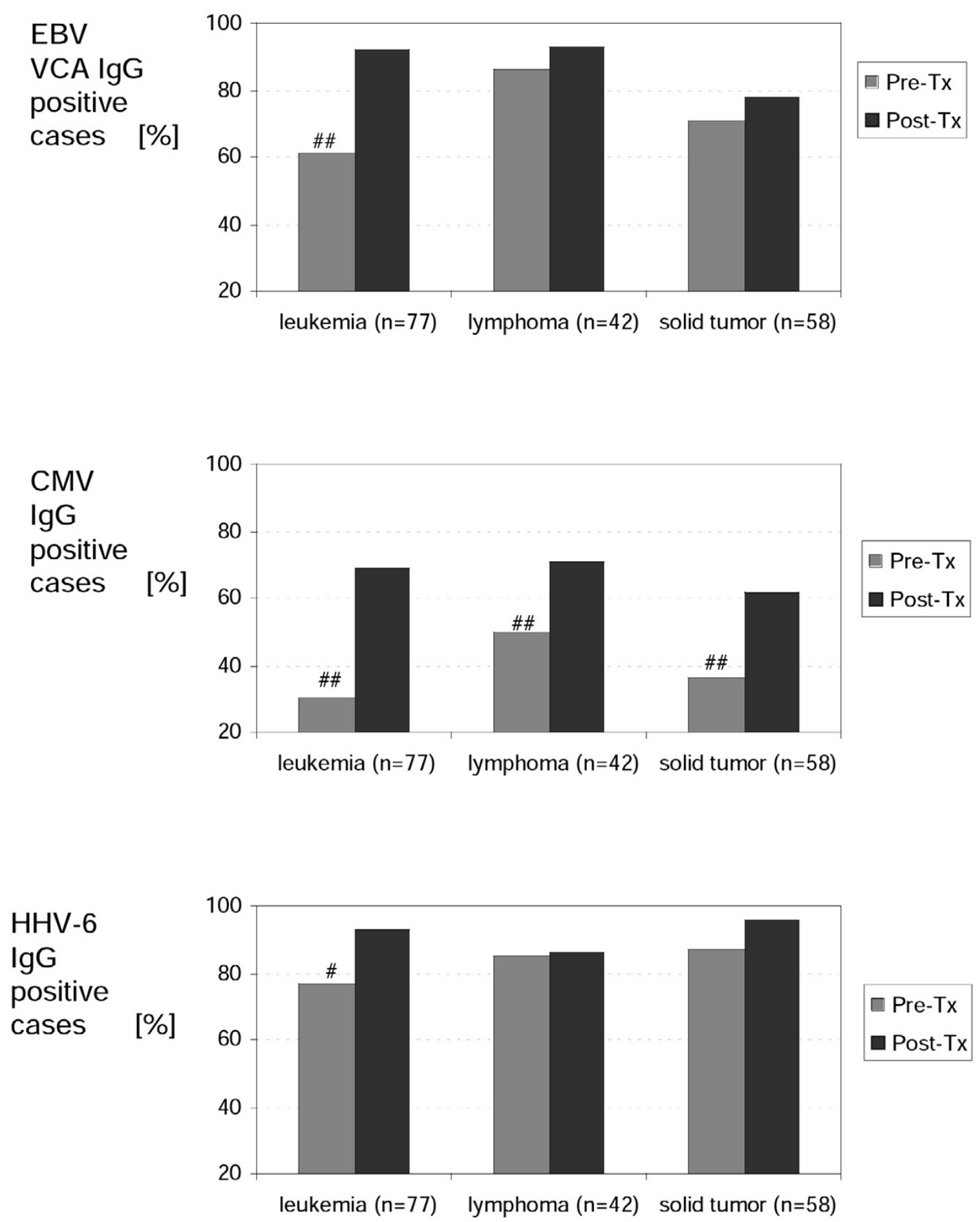

Figure 2

LH serology according to the diagnosis. \# $(p<0.05)$, \#\#(p<0.0I) statistically significant difference between a group of patients at the time of cancer diagnosis (Pre-Tx) and 2 months after the end of anticancer treatment (Post-Tx). 


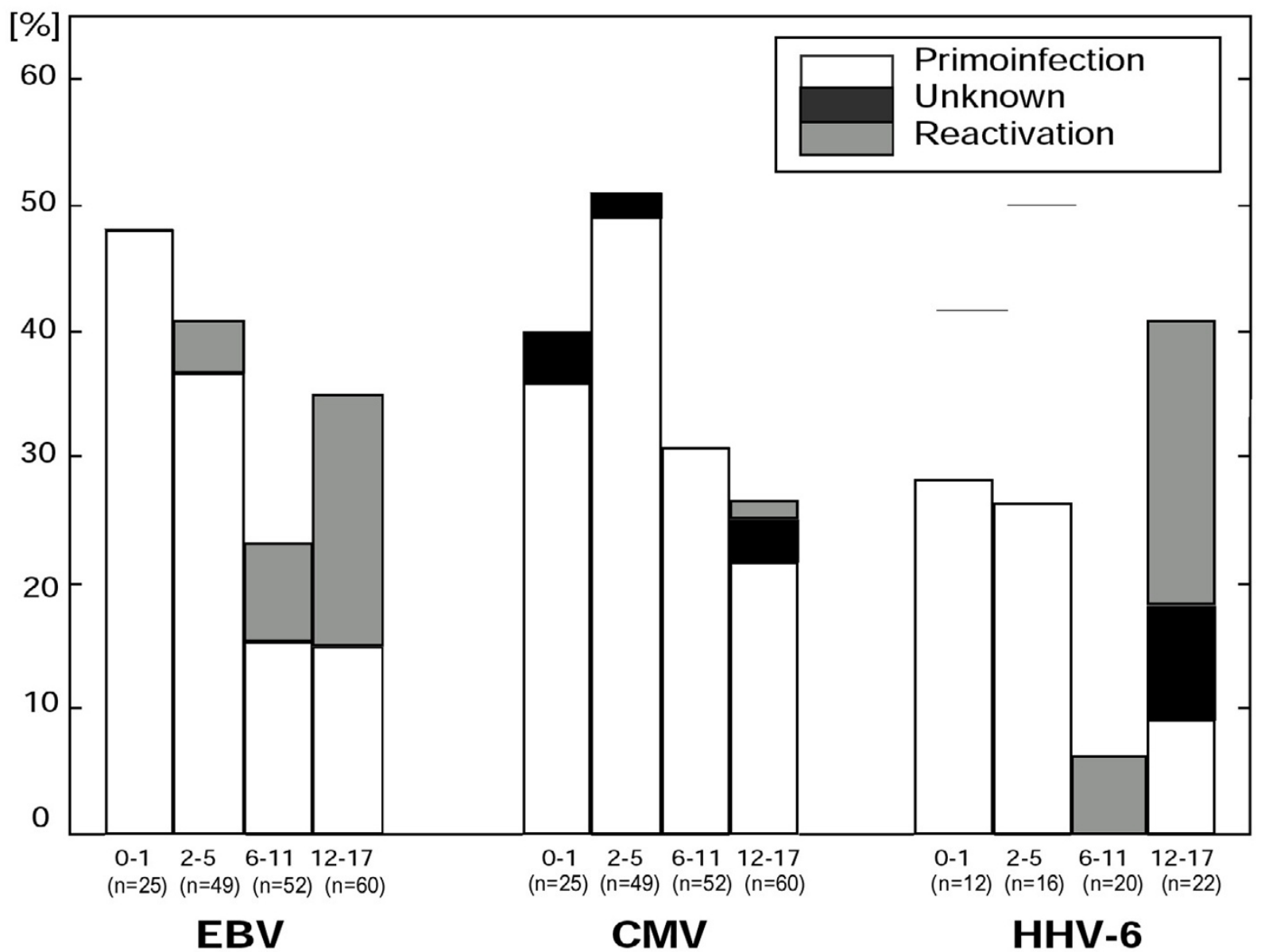

Figure 3

Primary infection and reactivation of LH. Percentage of seropositive cases (EBV VCA IgG; CMV IgG; HHV-6 IgG) in each age group (0-I, 2-5, 6-II and I2-I7 years old).

Table 3: Comparison of LH detection. EBV and CMV infections were studied in 1993-96 by serology only in II 6 patients. In I $997-99$ the combination of serology and DNA analysis of EBV, CMV and HHV-6 were performed in 70 patients. Percentage of positive cases is shown for each virus.

EBV CMV HHV-6

Symptomatic infection [\%] detected by

- serology only $(1993-96)(\mathrm{n}=116)$

- serology + DNA (1997-99) $(n=70)$

Laboratory infection [\%] detected by

- serology only $(1993-96)(n=116)$

- serology + DNA (1997-99) $(n=70)$

$\begin{array}{ccc}13.8 & 6.0 & - \\ 30.0 & 20.0 & 18.6 \\ & & \\ 33.6 & 34.5 & - \\ 37.1 & 38.6 & 32.9\end{array}$




\section{Analysis of LH DNA and comparison with LH serology} We examined 215 blood samples from 70 patients. Sixty four healthy individuals served as controls. Seventeen (24\%), 18 (26\%), and 21 (30\%) patients were PCR EBV, CMV and HHV-6, respectively, $(+)$ to $(+++)$ positive. In comparison, 2 (3\%), $1(2 \%)$, and 5 (8\%) healthy controls were PCR EBV, CMV and HHV-6, respectively, (+) positive; none was $(++)$ or $(+++)$ positive. All cases of PCR $(++)$ or $(+++)$ positive results obtained from 10,8 , and 13 patients with EBV, CMV and HHV-6 active symptomatic infection, respectively, corresponded with serological findings of recent infection occurring 1-5 weeks following the first PCR positive result. In case of PCR EBV, CMV and HHV-6 (+) positive result, the serology finding of recent infection corresponded in $7 / 7,6 / 10$ and $3 / 8$ patients, respectively. Four and 5 patients were PCR CMV and HHV-6 (+) positive, respectively, but lacking serological evidence of recent infection. Since they had symptomatic infection, we considered them being infected with a particular virus and all of them showed serological evidence of previous infection in post-treatment samples. Besides that, there were 4 patients PCR EBV negative who demonstrated recent infection by serology. One patient had coinfection of EBV and HHV-6 during anticancer treatment detected by PCR [EBV (+++) positive, HHV-6 (+)] with serological evidence of primary EBV infection and reactivation of HHV-6.

Data summarized in Table 3 provide the information about the differences in diagnosis of EBV and CMV infection. By combination of serology and DNA analysis, we were able to detect symptomatic infection more frequently in comparison to serology only $(\mathrm{p}=0.013$ for EBV; $\mathrm{p}=$ 0.007 for $\mathrm{CMV}$ ). As expected, the rates of "laboratory infection", defined as the sum of the cases with symptomatic infection and positive seroconversion for each virus, were not significantly different in these two groups. Laboratory EBV and CMV infection was present in 65 (34.9\%) and $66(35.4 \%)$ of 186 patients, respectively. Laboratory HHV-6 infection was present in 23 (32.9\%) of 70 patients.

\section{The influence of blood products on $\mathrm{LH}$ infection}

One hundred fifty six children $(83.9 \%)$ were given at least one blood product transfusion during treatment. Fifty four (34.6\%) and 57 (36.5\%) children out of 156 transfused children were infected with EBV and CMV, respectively. Eleven $(36.7 \%)$ and $9(30.0 \%)$ children out of 30 non-transfused children were infected with EBV and CMV, respectively. In addition, eighteen (29.5\%) out of 61 children transfused in the period from 1997 through 1999 were infected with HHV-6 while 5 (55.6\%) children out of 9 non-transfused children were infected with HHV-6. There was no statistically significant difference in the incidence of EBV $(p=0.64), \operatorname{CMV}(p=0.16)$ or HHV-6 ( $p=$
$0.24)$ infection in between transfused and non-transfused patients.

\section{Discussion}

Frequent infection with herpesviruses has long been recognized in patients undergoing allogeneic transplantation $[7,8]$ and in patients with acute leukemia $[1,2]$. In patients with acute leukemia it has been reported that as many as two thirds of seropositive patients can develop reactivation of herpes simplex virus infection during remission induction therapy [26]. The risk of CMV infection in acute leukemia patients was recognized almost 30 years ago [27] but is of particular concern in patients undergoing allogeneic transplantation $[2,28]$. EBV infection is frequently associated with post-transplantation lymphoproliferative disorders in $\mathrm{T}$ cell-depleted grafts [29]. As recently reported, HHV-6 can also be associated with bone marrow supression [30], encephalitis and pneumonitis $[7,8]$ after allogeneic transplantation.

Whether symptomatic LH infection occurs in chemotherapy- and/or radiotherapy-treated cancer patients has not been reported. This report demonstrates for the first time that $\mathrm{LH}$ infection affects more than one third of children treated for cancer. EBV and CMV infection occurred in almost $50 \%$ of children younger then 6 years during anticancer treatment. At the time of cancer diagnosis the rate of EBV and CMV seropositivity was not different in cancer patients and healthy controls. On the other hand, children in all age groups reached similar EBV and CMV seropositivity levels after anticancer treatment comparing to healthy adult controls. It suggests that children immunosupressed by chemotherapy and/or radiotherapy have high incidence of LH infection. As expected, primary infection was the most frequent in younger patients and reactivation occurred in older patients. In case of HHV-6 infection, which affects most of humans by the age of 2 years, we were surprised with low frequency of IgG antibodies in pre-treatment samples as compared with agematched healthy controls. There might be at least two possible mechanisms involved. First, due to either lower sensitivity to detect HHV-6 IgG antibodies by IFA or due to immune supression at the time of cancer diagnosis but similar pattern was not seen for EBV or CMV. Second, due to the possibility that prior infection with HHV-6 might be directly or indirectly protective against tumor development. This finding would be in agreement with Greaves hypothesis $[31,32]$ which predicted an increased risk of Bcell precursor ALL for those of higher socioeconomic level, firstborn children, and those with delayed or diminished exposure to common infections in infancy. When we studied our patient population based on cancer diagnosis, the only statistically significant difference between pre- and post-treatment samples was noticed in patients with leukemia ( $\mathrm{p}=0.0245$ ) but not in patients with lym- 
phoma or solid cancer (Figure 2). To our knowledge, there are no other data in the literature describing a protective effect of HHV-6 infection in infancy against leukemia. Further studies would be needed to test this association.

As previously demonstrated, the risk of transfusion-acquired CMV infection can be significantly reduced by the use of CMV-seronegative or filtered (white blood cell reduced) blood products [33]. In an effort to illustrate the role of leukodepleted blood transfusions in transmission of LH infection in pediatric oncology patients we studied both populations: a population of patients treated with leukodepleted irradiated blood products and a population of patients that did not required any blood transfusion during anticancer treatment. No statistically significant difference for each LH virus was found in these two groups. Those data are in accordance with recently published prospective study by Preiksaikis et al. [34] where the risk of transfusion-acquired CMV infection was estimated to be less than 1 in 698 donor exposures in children with cancer.

In the literature describing LH detection by PCR, the results vary widely since different protocols have been used in different biological materials [7-10,14]. PCR method was used in patients undergoing BMT or organ transplants but not in chemotherapy-only and/or radiotherapy-only treated patients. To our knowledge, this report demonstrates for the first time a correlation of serological results with viral load detected by PCR in children with different types of cancer. By using healthy controls and setting the threshold of PCR positive versus negative based on correlation with clinical symptoms and serology, acute LH infection could be identified in most of the cases. The highest incidence of LH infection occurred among patients with leukemia. It probably corresponds with the length of neutropenia and severity of immunosupression that is greater in patients treated for leukemia compared to patients with lymphoma or solid tumor.

\section{Conclusion}

This paper demonstrates that EBV, CMV and HHV-6 infection is frequent in children treated for cancer, is not transfusion-dependant, and is often associated with clinical symptoms. Combination of serology and PCR method in detection of symptomatic disease is superior to serology alone. Further studies are needed to identify patients at higher risk of severe LH infection to prevent disease-associated morbidity and to test the hypothesis that HHV-6 infection early in the infancy may be protective against leukemia in the frame of Greaves hypothesis.

\section{Abbreviations}

FN febrile neutropenia
LH lymphotropic herpesviruses

EBV Epstein-Barr virus

CMV cytomegalovirus

HHV-6 human herpesvirus 6

BMT bone marrow transplantation

\section{Competing interests}

None declared.

\section{Acknowledgement}

We gratefully acknowledge Dr. Daniel Bowers who made the language corrections of this manuscript and Dr. Barbara Foster who made the statistical analysis.

\section{References}

I. Chanock SJ, Pizzo PA: Infectious complications of patients undergoing therapy for acute leukemia: current status and future prospects. Semin Oncol 1997, 24:132-140

2. Wingard JR: Viral infections in leukemia and bone marrow transplant patients. Leuk Lymph 1993, I I:I I5-125

3. Pizzo PA, Poplack DG: Principles and practice of pediatric oncology. Lippincott Raven I997 I069-I I I4

4. Toren A, Ben-Bassat I, Rechavi G: Infectious agents and environmental factors in lymphoid malignancies. Blood Rev 1996, 1 0:89-94

5. Pizzo PA, Rochibaud KJ, Wesley R, Commers JR: Fever in the pediatric and young adult patient with cancer. $A$ prospective study of 1001 episodes. Medicine 1982, 6I:I53-165

6. Roguin A, Kasis I, Ben-Arush MW, Sharon R, Beraut M: Fever and neutropenia in children with malignant disease. Pedi Hematol Oncol 1996, I3:503-510

7. Ward KN: Infections due to the herpesvirus group in immunocompromised patients. Curr Opin Infect Dis 1998, I I:425-430

8. Griffiths PD, dark DA, Emery VC: Betaherpesviruses in transplant recipients. J Antimicrob Chemother 2000, 45:29-34

9. Maltezou HC, Kafetzis DA, Abisaid D, Mantzouranis EC, Chan KW, Rolston KV: Viral infections in children undergoing hematopoietic stem cell transplant. Pediatr Infect Dis J 2000, I 9:307-3 I2

10. Maeda Y, Teshima T, Yamada M, Shinagawa K, Nakao S, Ohno Y, Kojima K, Hara M, Nagafuji K, Hayashi S, et al: Monitoring of human herpesviruses after allogeneic peripheral blood stem cell transplantation and bone marrow transplantation. $\mathrm{Br} J \mathrm{Hae}$ matol 1999, I 05:295-302

II. Cone RW, Huang ML, Corey L, Zeh J, Ashley R, Bowden R: Human herpesvirus 6 infections after bone marrow transplantation: clinical and virological manifestations. J Infect Dis 1999, |79:3||-318

12. Armstrong JA, Evans AS, Rao N, Ho M: Viral infections in renal transplant recipients. Infect Immun 1976, I 4:970-975

13. Sia IG, Patel R: New strategies for prevention and therapy of cytomegalovirus infection and disease in solid-organ transplant recipients, Clin Microbiol Rev 2000, I 3:83-I2I

14. Gautheret-Dejean A, Aubin JT, Poirel L, Poirel L, Huraux JM, Nicolas IC, Rozenbaum W, Agut H: Detection of human Betaherpesvirinae in saliva and urine from immunocompromised and immunocompetent subjects. J Clin Microbiol 1997, 35:1600-1603

I5. Cremer KJ: Role of HIV I and other viruses in malignancies associated with acquired immunodeficiency disease syndrome. J Natl Cancer Inst 1990, 82:1016-1019

16. Kawa K: Epstein-Barr virus-associated diseases in humans. Internat J Hematol 2000, 7I: 108-I I7

17. Han KJ, Jung IS, Kim CK, Park SK, Kim DW, Baick SH, Won JH, Hong DS, Hwang SD, Moon C, Park HS: A case of CMV disease of the jejunum in a patient with non-Hodgkin's lymphoma. Korean J Intern Med 1998, I 3:143-146

18. Fujita H, Maruta A, Tomita N, Taguchi J, Sakai R, Shimizu A, Harada M, Ogawa K, Kodama F, Okubo T: Human herpesvirus-6-associ- 
ated exanthema in a patient with acute lymphoblastic leukaemia. Br J Haematol 1996, 92:947-949

19. Rantala H, Mannonen L, Ahtiluoto S, Linnavuori K, Herva R, Vaheri A, Koskiniemi M: Human herpesvirus- 6 associated encephalitis with subsequent infantile spasms and cerebellar astrocytoma. Dev Med Child Neurol 2000, 42:4I 8-42I

20. Luka J, Chase RC, Pearson G: A sensitive enzyme-linked immunosorbent assay (ELISA) against the major EBV-associated antigens. I Immunol Methods 1984, 67:145-149

21. Cappel R, de Cuyper F, de Braekeleer J: Rapid detection of IgG and IgM antibodies for cytomegalovirus by the enzyme linked immunosorbent assay (ELISA). Arch Virol 1978, 58:253258

22. Robert C, Agut H, Aubin JT: Detection of antibodies to human herpesvirus-6 using immunofluorescence assay. Res Virol 1990, | 41:545-555

23. Pershing DH, Smith TF, TEnover FC, White TJ: Diagnostic Molecular Microbiology. American Society for Microbiology, Washington, D.C. 1993

24. Saito I, Servenius B, Compton T, Fox RI: Detection of EBV DNA by PCR in blood and tissue biopsies from patients with Sjorgen's syndrome. J Exp Med 1989, 169:2191-2198

25. Andel J: Statistical methods. Matfyzpress, Prague 1994I54-156

26. Bustamante $C$, Vade $\mathrm{J}$ : Herpes simplex virus infection in the immunocompromised cancer patient. J Clin Oncol 1991, 9:19031915

27. Henson D, Siegel S, Fucillo D, Mathew E, Levine AS: Cytomegalovirus infections during acute childhood leukemia. J Infect Dis 1972, I 26:469-48|

28. Broers AEC, van der Holt R, van Esser JW, Gratama JW, Henzer-Logmans S, Kuenen-Boumeester V, Lowengerg B, Cornelissen J]: Increased transplant-related morbidity and mortality in CMVseropositive patients despite highly effective prevention of CMV disease after allogeneic $T$ cell-depleted stem cell transplantation. Blood 2000, 95:2240-2245

29. Moisier DE: Epstein-Barr virus and lymphoproliferative disease. Curr Opin Hematol 1999, 6:25-29

30. Singh N, Carrigan DR, Gayowski T, Marino IR: Human herpesvirus 6 infection in liver transplant recipients - documentation of pathogenicity. Transplantation 1997, 64:674-678

31. Greaves MF: Speculations on the cause of childhood acute lymphoblastic leukemia. Leukemia 1988, 2:120-125

32. Greaves MF, Alexander FE: An infectious etiology for common acute lymphoblastic leukemia in childhood? Leukemia 1993, 7:349-360

33. Bowden RA, Slichter SJ, Sayers M, Weisdorf D, Cays M, Schoch G, Banaji M, Haake R, Welk K, Fisher L: A comparison of filtered leukocyte-reduced and cytomegalovirus (CMV) seronegative blood products for the prevention of transfusion-associated CMV infection after marrow transplant. Blood 1995, 86:35983603

34. Preiksaitis JK: The cytomegalovirus - " safe" blood product: Is leucoreduction equivalent to antibody screening? Transfusion Medicine Reviews 2000, 14:1 12-13
Publish with BioMed Central and every scientist can read your work free of charge

"BioMedcentral will be the most significant development for disseminating the results of biomedical research in our lifetime."

Paul Nurse, Director-General, Imperial Cancer Research Fund

Publish with BMC and your research papers will be:

- available free of charge to the entire biomedical community

- peer reviewed and published immediately upon acceptance

- cited in PubMed and archived on PubMed Central

- yours - you keep the copyright

Submit your manuscript here:

http://www.biomedcentral.com/manuscript/ 